\title{
Capsule Commentary on Chen et al., A Randomized Trial of Displaying Paid Price Information on Imaging Study and Procedure Ordering Rates
}

\author{
Zhen Wang, PhD \\ J Gen Intern Med 32(4):472 \\ DOI: $10.1007 / \mathrm{s} 11606-017-3984-3$ \\ (๑) Society of General Internal Medicine 2017
}

Division of Health Care Policy and Research, Department of Health Sciences Research, Mayo Clinic, Rochester, MN, USA.

I $\mathrm{n}$ a randomized controlled trial, Chien et al. ${ }^{1}$ evaluated the effectiveness of physician-targeted price transparency on physicians' ordering rate for common imaging studies and procedures. A total of 1205 physicians in an accountable care organization (ACO) (Atrius Health) were block randomized to receive no price display, a single price, or an internal and external price on the test-ordering screen of their electronic health record. The authors found no significant difference across the groups on overall, inappropriate, or appropriate orders and orders for tests to be conducted internally.

The study is remarkable in several respects. It is the largest randomized controlled trial in this area with sufficient sample size to detect differences and minimize potential bias across groups. It was conducted in real clinical settings with a relatively long study period. More importantly, the study was conducted within the context of ACO. Created by the Patient Protection and Affordable Care Act, ACOs are incentivized to reduce cost while maintaining or improving quality of care. It is reasonable to assume that physicians within ACOs may be more cost conscious and willing to reduce medical waste if they are given convenient ways to access price information. However, this study rejected this assumption and found that sharing price information with physicians may not change physicians' ordering behavior.
It is important to note some limitations to this study. First, the patient population included significantly fewer Medicaid and Medicare beneficiaries compared to the US or Massachusetts population. ${ }^{2}$ Wealthier patients and physicians treating those patients are less sensitive to medical costs. Second, most of the physicians in ACOs are still compensated by productivity. ${ }^{3}$ It would be interesting to know whether completely salary-based physicians would act differently. In these regards, I agree with the authors that further research is necessary to evaluate "contextual, motivational, and behavioral factors" that may affect the study findings.

Corresponding Author: Zhen Wang, PhD; Division of Health Care Policy and Research, Department of Health Sciences Research, Mayo Clinic, Rochester, MN, USA (e-mail: Wang.Zhen@mayo.edu).

\section{Compliance with Ethical Standards:}

Conflict of Interest: The author has no conflicts of interest with this article.

\section{REFERENCES}

1. Chien A, Lehmann L, Hatfield L, Koplan K, Petty C, Sinaiko A, et al. A randomized trial of displaying paid price information on imaging study and procedure ordering rates. J Gen Intern Med. 2016. doi:10.1007/s11606016-3917-6.

2. The Henry J. Kaiser Family Foundation. State Health Facts: Health Insurance Coverage of the Total Population. 2014. http://kff.org/other/state-indicator/ total-population/?currentTimeframe $=1 \&$ selectedDistributions=medicaid-medicare. Accessed November 11, 2016.

3. Ryan AM, Shortell SM, Ramsay PP, Casalino LP. Salary and quality compensation for physician practices participating in accountable care organizations. Ann Fam Med. 2015;13(4):321-324. doi:10.1370/ afm. 1805. 